\title{
Chronic Avulsion of the Proximal Rectus Femoris Tendon with Significant Defect: A Successful Surgical Management
}

\author{
Mathieu Angers-Goulet ${ }^{1 *}$, Nicolas Janelle ${ }^{2}$ and Étienne L Belzile ${ }^{1,3}$ \\ ${ }^{1}$ Department of Surgery, Université Laval, Canada \\ ${ }^{2}$ Department of Kinesiology, Université Laval, Canada \\ ${ }^{3}$ Department of Orthopaedic Surgery, CHU de Québec-Université Laval, Canada
}

*Corresponding author: Mathieu Angers-Goulet, MD, Orthopaedic Surgeon Resident, CHU de, Québec-Université Laval, 1401, 18e rue, Quebec City, QC G1J 1Z4, Canada

Submission: 監 August 23, 2018; Published: 監 September 24, 2018

\begin{abstract}
Background: Rupture of the proximal rectus femoris tendon has been well documented in the literature because of a bony avulsion of the anteroinferior iliac spine predominantly in the active adolescent population. Most of these ruptures are treated non-operatively with good functional outcomes. However, when conservative treatments fail, surgery is an option.

Purpose: To describe a rare case of successful surgical management of a chronic ruptured proximal rectus femoris tendon.

Results: The patient progressively returned to competitive sports without any symptoms at four months post tendon repair. At final follow-up two years after surgical repair, the patient has a University of California, Los Angeles activity score of 10, and a Non-Arthritic Hip Score of 95/100.

Conclusion: Tendon avulsion of the rectus femoris muscle is a rare entity in the adult population. Surgical management of chronic tendon avulsion of the rectus femoris proved to be efficient and can be recommended when conservative treatment fails.

Keywords: Rectus femoris; Avulsion; Surgical Repair; Chronic
\end{abstract}

\section{Introduction}

Rupture of the proximal rectus femoris tendon has been well documented in the literature as a result of a bony avulsion of the antero-inferior iliac spine (AIIS) predominantly in the active adolescent population. Most of these ruptures are treated non-operatively with good functional outcomes. The following is a rare case of a chronic tendon rupture of the direct head of the rectus femoris muscle presenting with significant muscle retraction in a soccer player managed surgically.

\section{Case}

A 23-year old male competitive college level soccer player with no past medical history consulted for chronic left hip pain that started more than a year earlier. The initial onset of his symptoms was due to an acute hyperextension and external rotation injury of his hip while trying to strike the ball with his left foot 14 months ago. He recalled having his toes struck the ground first causing a shooting and stretching pain up his left thigh. A quadriceps strain was diagnosed at the time, and the player returned to play a couple months later, after a short period of immobilization, no weight bearing and physical therapy. Unfortunately, the patient continued to experience mild to moderate pain localized at the supero-anteri or aspect of his left thigh. Pain was induced with hip flexion while running or striking the ball.

On physical exam, the upper part of the left quadriceps was atrophic at the tensor fascia latae and sartorius interval. Acute pain was solicited with palpation of the AIIS. Quadriceps forces were slightly diminished to $4+/ 5$ on the left side with symmetric $0^{\circ}$ to $110^{\circ}$ of active hip flexion. Hamstring and gluteal muscles forces were normal.

The standing and lying down radiographs of his pelvis and left hip revealed a normal hip joint, with no sign of heterotopic calcification. The magnetic resonance of the left hip and thigh revealed a complete tear of direct head of the rectus femoris muscle at its proximal myotendinous junction (Figure 1). The proximal third of the rectus femoris appeared atrophic with fatty replacement. Proximal retraction was measured at $10 \mathrm{~cm}$. No other muscle or bony anomalies were observed. Since the conservative approach remained unsatisfactory for his athletic requirements, surgical repair was proposed to the patient with the expectative that his condition would either improve or remain the same after surgical repair. The patient understood these limitations and underwent surgery three months later. 


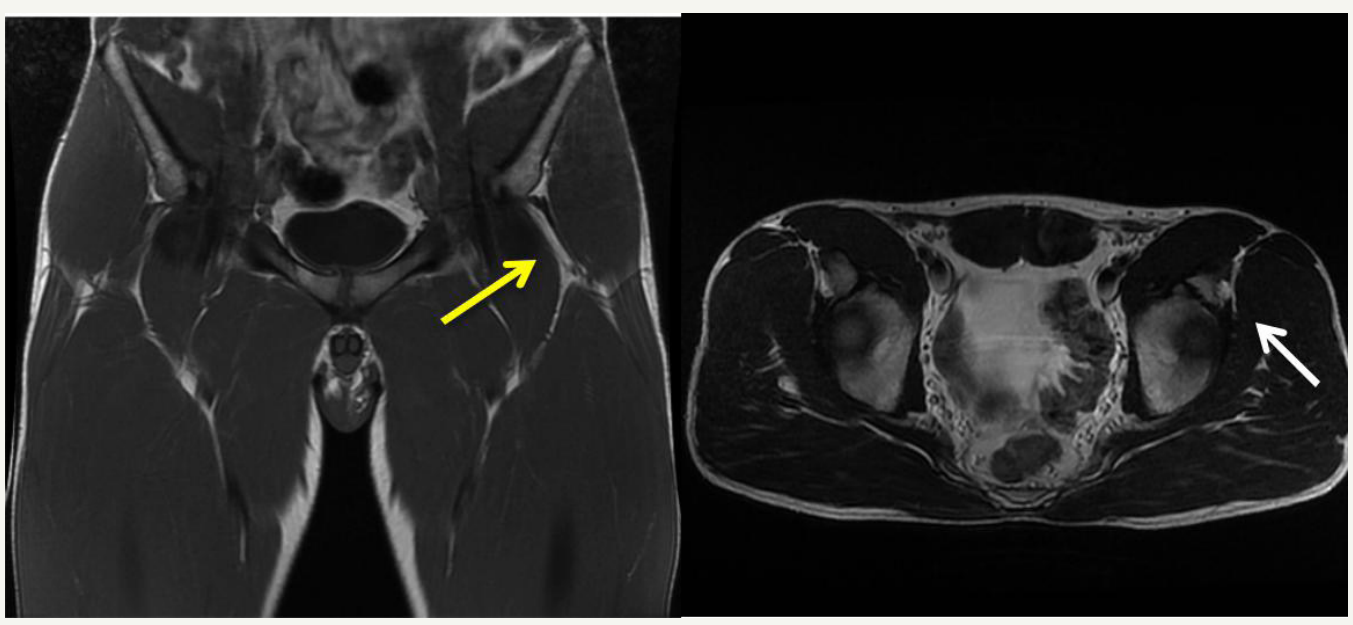

Figure 1: MRI showing left hip rectus femoris tendinous avulsion. Yellow arrow shows retracted rectus tendon on T1 coronal view while the white arrow points to the atrophic and fatty replacement in the rectus on an axial T2 Fat saturation view.

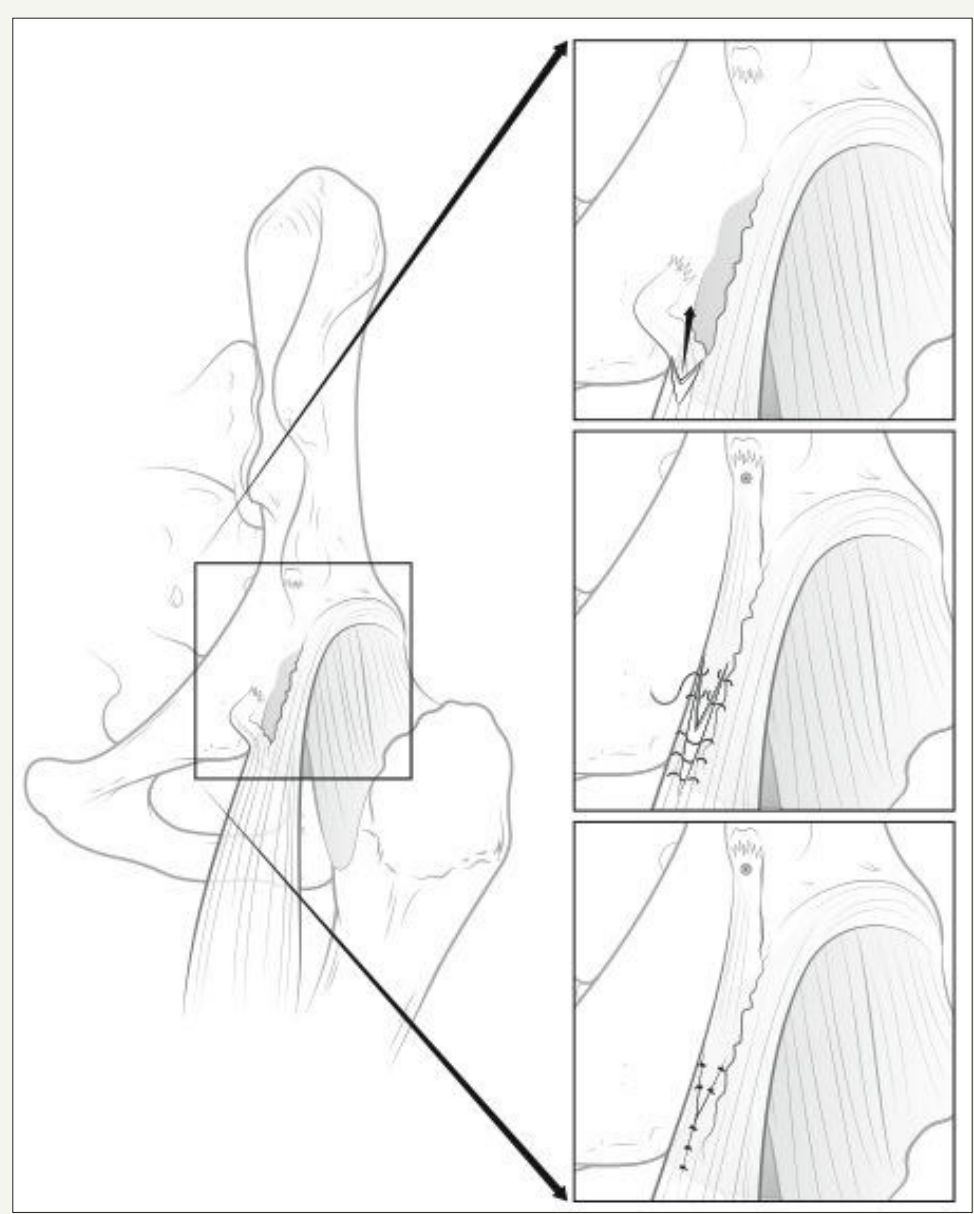

Figure 2: Artistic rendition of a longitudinal tear between direct and indirect head of the rectus femoris tendon of a left hip depicted as an obturator view of the iliac wing. A V-Y advancement technique (A and B) is shown to demonstrate proximal migration of the tendinous stump for direct repair to the AIIS using a bony anchor (C).

A classic anterior approach of the hip (Smith-Peterson) was used to explore the injury site and to dissect the scar tissues around the proximal aspect of rectus femoris muscle. After mobilizing the ruptured direct head of the proximal tendon, we observed that the indirect head remained intact at its origin on the superior and lateral aspect of the acetabulum. The signal highlighted by the magnetic resonance imaging at the level of the myotendinous junction was in fact a longitudinal tear in the rectus tendon between the distally 
migrated direct head and the intact indirect head (Figure 2A). The gap between the direct head and the AIIS was approximately $10 \mathrm{~cm}$. With the hip at $45^{\circ}$ of flexion, the direct head was mobilized proximally using a V-Y technique (Figure 2B), regaining full length, and re-attached solidly to the AIIS using a $5.0 \mathrm{~mm}$ bone anchor (Arthrex Inc., Naples, Florida, USA) (Figure 2C). The hip was immobilized in a rigid hip abduction brace with the hip flexed at $40^{\circ}$ and with abduction locked at $10^{\circ}$. Surgery was well tolerated, and no complications occurred except for a residual hypoesthesia at the incision site due to stretching of a medial branch of the lateral cutaneous femoral nerve during the surgical approach.

Post-operatively, the patient was immobilized for 10 days at $40^{\circ}$ of hip flexion before initiating physical therapy and progressive movements from 30 to $40^{\circ}$ of hip flexion. At four weeks, the brace was removed, and the patient was able to reach full extension of his hip gradually with mild residual pain and quadriceps tightness. Full weight bearing without the brace was allowed, and he started stationary bicycle. At two months, the patient was allowed full range of hip motion, and reinforcement exercises with elastic bands were initiated. Finally, the patient was pain free and reached full range of hip motion after three months. His Non-Arthritic Hip Score (NAHS) was 95/100. Forces were symmetrical for both hips and knees. The patient progressively returned to competitive sports without any symptoms at four months post tendon repair. At final follow-up two years after surgical repair, the patient has a University of California, Los Angeles (UCLA) activity score of 10, and a NAHS of 95/100. He experiences slight hip flexor stiffness when warming up and feels unable to achieve pre-injury sprinting speed.

\section{Discussion}

Groin injuries account for 2 to $5 \%$ of traumatic injuries in athlete and have a broad differential diagnosis including muscle strains, tendon avulsion fractures, stress fractures, osteitis pubis, abdominal wall defects, hip and labral pathologies, sports hernias, snapping syndromes and trochanteric bursitis [1-7]. Muscle strains are the most common lower limb injury in this athletic population [1,3-7]. The hamstrings and the rectus femoris muscles are the most commonly involved [8]. Clinical history, mechanism of injury and physical examination are still the cornerstone to the diagnosis. With advancement in technologies, magnetic resonance imaging proved to be the investigation of choice to confirm soft tissue lesions and for preoperative planning [9], even though plain radiograph, echography and computed tomodensitometry scan are still valuable $[10,11]$. Most muscle strain injuries are treated successfully non-operatively with immobilization and aggressive physiotherapy regimen [12-14]. Surgical intervention is mostly reserved when the conservative treatment has failed or when specific indications and patient related requirements prompt acute repair $[15,16]$.

Rectus femoris tendon avulsion at its origin, the AIIS, is a rare entity [17-19]. Anatomical, histological and bio kinematic factors predispose the rectus tendon for this type of injury [20,21]. All four quadriceps muscles are inserted on the anterior tibial tuberosity via the patello- quadricipital tendon complex, while only the rectus femoris muscle origins from a pelvic insertion via its direct and indirect head. The vastus muscles (medial, lateral and intermediate) originate from various positions along the femoral shaft. The origins of the direct and indirect head joining to form the conjoint tendon of the rectus femoris muscle are well documented $[19,20,22,23]$. The direct head stem from the AIIS crossing the anterior margin of the acetabulum while the indirect head lays on the superior ridge of the acetabular in a constant pattern [24]. Spanning two joints (hip and knee) and with high type II collagen fibers concentration, the rectus femoris muscle is at greater risk of tendon rupture than the other quadriceps muscles $[21,25]$. Therefore, rapid eccentric contraction of the quadriceps at maximum hip extension and knee flexion puts it at greatest risk [20,26-28]. Such mechanisms are replicated in sprinting and kicking which are the typical sports faced with these injuries. In their magnetic resonance study of 17 cases of proximal rectus femoris tendon injuries, Ouellette et al. [19] assessed anatomical strain patterns. Sixteen cases had indirect head injuries, 5 had direct head injuries and the conjoint tendon was injured in only 3 cases. Therefore, a progressing sequence model of injury from the indirect head, to the direct head, to the conjoint tendon of the rectus femoris was proposed.

Most rectus femoris avulsions occur in the pediatric athletic population [18,29-31]. Adolescents are more prone to pelvic tuberosity avulsion since their tendon strength is greater than the epiphyseal strength [18]. Rossi \& Dragoni [18] evaluated 203 cases of bony avulsion of the pelvis in the adolescent athletic population. AIIS avulsion accounted for $22 \%$ of the injuries and was the second most frequent injury behind hamstrings avulsion. Soccer (40\%), athletics $(22 \%)$ and tennis $(22 \%)$ were the most frequent sport causing AIIS avulsion. Only two of the 45 patients with AIIS avulsion underwent surgical repair. Unlike the pediatric population, strains reported in the adult population occur mostly at the myotendinous junction or at the tendon itself in cases of degenerative diseases [32-34]. Gamradt et al. [17] reported 11 cases of rectus femoris avulsion injuries over the 1986 and 2006 period in the American National Football League (NFL). All were treated non-operatively with full return to play within 6 to 12 weeks. Few complications to conservative treatment were reported in the adult or pediatric population such as heterotopic ossification, AIIS non-union, chronic pain and decreased hip range of motion [35].

Surgical intervention for complete rectus tendon or AIIS avulsion has been reserved for specific indications such as significant bony fragment displacement, severe soft-tissue damage, associated labral tear, both tendon ruptures, AIIS non-union, heterotopic ossification, chronic pain and high postoperative goals in competitive athletes [18,36-45]. Only few cases of acute and chronic complete tendon strains without AIIS avulsions have been treated surgically following specific indications with good results in the adult population $[36,37,40,41]$. All were approached via the anterior muscle interval (Smith Peterson) with different fixation techniques to reduce the bony fragment or to repair the tendon. Direct permanent 
sutures, sutures through bone tunnels, cerclage wiring, cancellous screws with washer, and bone anchors were used in these cases with good functional results [42-45]. Augmentation with plasma rich in growth factors at the end of the procedure was also suggested with good results [36,43]. Double-row anchors technique was also suggested similarly to rotator cuff repair in shoulder surgeries [42]. Lateral cutaneous femoral nerve hypoesthesia was the only specific surgical complication reported and all patients recovered from it. It was acknowledged that this complication, similarly to our case, results from the surgical approach rather than the tendon fixation. The recent technical note by Dean et al. suggest the possible indications, surgical approach, technical procedure and post-operative management of proximal rectus femoris tendon rupture [42].

For the surgical management of this case, we elected to use a combination of hip flexion and a V- Y tendinous advancement to palliate the $10 \mathrm{~cm}$ gap between the direct head and the AIIS [46] Tendon autograft or allograft had been considered and would have represented other valid options [46]. Since local tissues were judged as sufficient, we felt that the V-Y technique was preferable than creating another insult elsewhere or introducing an interposition graft. The direct tendon was advanced to close a $4 \mathrm{~cm}$ gap after the V-Y technique. Therefore, rectus femoris muscular stretching as well as hip flexion at $40^{\circ}$ was necessary to restore full length. Only one acute case reported encountering a similar significant tendinous retraction $(8 \mathrm{~cm})$ [37]. It was a partial tear of the direct tendon with some proximal tendon fibers left anchored to the AIIS. A side-to-side tendon repair technique was enough for the repair in that case. The choice of suture anchor fixation was constant with similar cases [36,37], except for Straw [32] who used direct sutures and for Bottoni [41] who used bone tunnels. The later cases did not present with significant muscle retraction however. We believe that suture anchors were a valid option to fix the tendon solidly for our case since significant stress was applied to our repair due to length restoration with the VY technique.

To our knowledge, no immobilization and rehabilitation protocols have been established for the surgical management of this type of injury since there are only few cases reported. All other surgical cases used a knee immobilization device with toe-touch or a no weight-bearing regimen for 4 to 8 weeks, followed by progressive rehabilitation [36,37,41,45,47]. Return to activity varied between 4 to 8 months, which was like conservative management $[17,35,38,48]$. In our case, due to significant retraction and the chronic aspect of the injury, hip immobilization at $40^{\circ}$ of flexion in a hip brace was inevitable to reduce tendon tension at the repair site and to restore muscle length gradually. In our opinion, a knee immobilizer does not offer adequate control of the hip position and thus any protection to the repair site. The patient progressively returned to soccer practice after three months and was able to play with full capacity at four months.

\section{Conclusion}

Tendon avulsion of the rectus femoris muscle is a rare entity in the adult population. In the acute setting, surgical management has yet to prove a reduction in rehabilitation time over the conserva- tive treatment or an improvement in functional outcomes. Further research is indicated to support the surgical option in the acute rectus femoris tendon injury. In the case presented, failure of the conservative treatment due to significant muscle retraction and the objective to return to a high-level competitive soccer was dual surgical indications. Surgical management of chronic tendon avulsion of the rectus femoris proved to be efficient and can be recommended when conservative treatment fails.

\section{References}

1. Renstrom P, Peterson L (1980) Groin injuries in athletes. Br J Sports Med 14(1): 30-36.

2. Renstrom PA (1992) Tendon and muscle injuries in the groin area. Clin Sports Med 11(4): 815-831.

3. Ekstrand J, Hilding J (1999) The incidence and differential diagnosis of acute groin injuries in male soccer players. Scand J Med Sci Sports 9(2): 98-103.

4. Morelli V, Weaver V (2005) Groin injuries and groin pain in athletes: part 1. Prim Care 32(1): 163-183.

5. Morelli V, Smith V (2001) Groin injuries in athletes. American family physician 64(8): 1405-1414.

6. Morelli V, Espinoza L (2005) Groin injuries and groin pain in athletes: part 2. Prim Care 32(1): 185-200.

7. Anderson K, Strickland SM, Warren R (2001) Hip and groin injuries in athletes. Am J Sports Med 29(4): 521-533.

8. Garrett WE, Rich FR, Nikolaou PK, Vogler JB (1989) Computed tomography of hamstring muscle strains. Med Sci Sports Exerc 21(5): 506-514.

9. Ahn JM, El-Khoury GY (2007) Role of magnetic resonance imaging in musculoskeletal trauma. Top Magn Reson Imaging 18(3): 155-168.

10. Overdeck KH, Palmer WE (2004) Imaging of hip and groin injuries in athletes. Semin Musculoskelet Radiol 8(1): 41-55.

11. De Paulis F, Cacchio A, Michelini O, Damiani A, Saggini R (1998) Sports injuries in the pelvis and hip: diagnostic imaging. Eur J Radiol 27(1): S49-S59.

12. Serner A, van Eijck CH, Beumer BR, Holmich P, Weir A, et al. (2015) Study quality on groin injury management remains low: a systematic review on treatment of groin pain in athletes. Br J Sports Med 49(12): 813.

13. Robertson BA, Barker PJ, Fahrer M, Schache AG (2009) The anatomy of the pubic region revisited: implications for the pathogenesis and clinical management of chronic groin pain in athletes. Sports Med 39(3): 225234.

14. Fricker PA (1997) Management of groin pain in athletes. Br J Sports Med 31(2): 97-101.

15. Meyers WC, Lanfranco A, Castellanos A (2002) Surgical management of chronic lower abdominal and groin pain in high-performance athletes. Curr Sports Med Rep1(5): 301-305.

16. Karlsson J, Sward L, Kalebo P, Thomee R (1994) Chronic groin injuries in athletes. Recommendations for treatment and rehabilitation. Sports Med17(2): 141-148.

17. Gamradt SC, Brophy RH, Barnes R, Warren RF, Thomas Byrd JW, et al. (2009) Nonoperative treatment for proximal avulsion of the rectus femoris in professional American football. Am J Sports Med 37(7): 13701374

18. Rossi F, Dragoni S (2001) Acute avulsion fractures of the pelvis in adolescent competitive athletes: prevalence, location and sports distribution of 203 cases collected. Skeletal Radiol 30(3): 127-131. 
19. Ouellette H, Thomas BJ, Nelson E, Torriani M (2006) MR imaging of rectus femoris origin injuries. Skeletal Radiol 35(9): 665-672.

20. Hasselman CT, Best TM, Hughes CT, Martinez S, Garrett WE (1995) An explanation for various rectus femoris strain injuries using previously undescribed muscle architecture. Am J Sports Med 23(4): 493-499.

21. Stalberg E, Borges O, Ericsson M, Essen-Gustavsson B, Fawcett PR, et al. (1989) The quadriceps femoris muscle in 20-70-year-old subjects: relationship between knee extension torque, electrophysiological parameters, and muscle fiber characteristics. Muscle Nerve 12(5): 382389.

22. Zeiss J, Saddemi SR, Ebraheim NA (1992) MR imaging of the quadriceps tendon: normal layered configuration and its importance in cases of tendon rupture. AJR Am J Roentgenol 159(5): 1031-1034.

23. Philippon MJ, Michalski MP, Campbell KJ, Goldsmith MT, Devitt BM, et al. (2014) An anatomical study of the acetabulum with clinical applications to hip arthroscopy. J Bone Joint Surg Am 96(20): 1673-1682.

24. Hapa O, Bedi A, Gursan O, Akar MS, Guvencer M, et al. (2013) Anatomic footprint of the direct head of the rectus femoris origin: cadaveric study and clinical series of hips after arthroscopic anterior inferior iliac spine/ subspine decompression. Arthroscopy 29(12): 1932-1940.

25. Ivy JL, Withers RT, Brose G, Maxwell BD, Costill DL (1981) Isokinetic contractile properties of the quadriceps with relation to fiber type. Eur Appl Physiol Occup Physiol 47(3): 247-255.

26. Barfield WR (1998) The biomechanics of kicking in soccer. Clin Sports Med 17(4): 711-728,

27. Young RP, Marteniuk RG (1998) Stereotypic muscle-torque patterns are systematically adopted during acquisition of a multi-articular kicking task. J Biomech 31(9): 809-816.

28. Young RP, Marteniuk RG (1995) Changes in inter-joint relationships of muscle moments and powers accompanying the acquisition of a multiarticular kicking task. J Biomech 28(6): 701-713.

29. Schothorst AE (1978) Avulsion fractures of the inferior-anterior iliac spine. Archivum chirurgicum Neerlandicum 30(1): 55-59.

30. Saluan PM, Weiker GG (1997) Avulsion of the anterior inferior iliac spine. Orthopedics 20(6): 558-559.

31. Mader TJ (1991) Avulsion of the rectus femoris tendon: an unusual type of pelvic fracture. Pediatr Emerg Care 6(3): 198-199.

32. Tidball JG, Salem G, Zernicke R (1993) Site and mechanical conditions for failure of skeletal muscle in experimental strain injuries. J Appl Physiol 74(3): 1280-1286

33. Nikolaou PK, Macdonald BL, Glisson RR, Seaber AV, Garrett WE (1987) Biomechanical and histological valuation of muscle after controlled strain injury. Am J Sports Med 15(1): 9-14.
34. Kannus P, Natri A (1997) Etiology and pathophysiology of tendon ruptures in sports. Scand J Med Sci Sports 7(2): 107-112.

35. Park CK, Zlomislic V, Du J, Huang BK, Chang EY, et al. (2018) Nonoperative management of a severe proximal rectus femoris musculotendinous injury in a recreational athlete: a case report. PM R.

36. Irmola T, Heikkila JT, Orava S, Sarimo J (2007) Total proximal tendon avulsion of the rectus femoris muscle. Scand J Med Sci Sports 17(4): 378-382.

37. Langer PR, Selesnick H (2010) Proximal rectus femoris avulsion in an elite, olympic-level sprinter. Am J Orthop 39(11): 543-547.

38. Rajasekhar C, Kumar SK, Bhamra MS (2001) Avulsion fractures of the anterior inferior iliac spine: the case for surgical intervention. Int Orthop 24(6): 364-365.

39. Resnick JM, Carrasco CH, Edeiken J, Yasko AW, Ro JY, et al. (1996) Avulsion fracture of the anterior inferior iliac spine with abundant reactive ossification in the soft tissue. Skeletal Radiol 25(6): 580-584.

40. Straw R (2003) Surgical repair of a chronic rupture of the rectus femoris muscle at the proximal musculotendinous junction in a soccer player. $\mathrm{Br}$ J Sports Med 37(2): 182-184

41. Bottoni CR, D'Alleyrand JC (2009) Operative treatment of a complete rupture of the origination of the rectus femoris. Sports health 1(6): 478480.

42. Dean CS, Arbeloa-Gutierrez L, Chahla J, Pascual-Garrido C (2016) Proximal rectus femoris avulsion repair. Arthrosc Tech 5(3): e545-e549.

43. Garcia VV, Duhrkop DC, Seijas R, Ares O, Cugat R (2012) Surgical treatment of proximal ruptures of the rectus femoris in professional soccer players. Arch Orthop Trauma Surg 132(3): 329-333.

44. Sonnery-Cottet B, Barbosa NC, Tuteja S, Gardon R, Daggett M, et al. (2017) Surgical management of rectus femoris avulsion among professional soccer players. Orthop J Sports Med 5(1): 2325967116683940.

45. Ueblacker P, Muller-Wohlfahrt HW, Hinterwimmer S, Imhoff AB, Feucht MJ (2015) Suture anchor repair of proximal rectus femoris avulsions in elite football players. Knee Surg Sports Traumatol Arthrosc 23(9): 25902594.

46. Maffulli N, Ajis A (2008) Management of chronic ruptures of the Achilles tendon. J Bone Joint Surg Am 90(6): 1348-1360.

47. Straw R, Colclough K, Geutjens G (2003) Surgical repair of a chronic rupture of the rectus femoris muscle at the proximal musculotendinous junction in a soccer player. Br J Sports Med 37(2): 182-184.

48. Hsu JC, Fischer DA, Wright RW (2005) Proximal rectus femoris avulsions in national football league kickers: a report of 2 cases. Am J Sports Med 33(7): 1085-1087.
Creative Commons Attribution 4.0 International License

For possible submissions Click Here

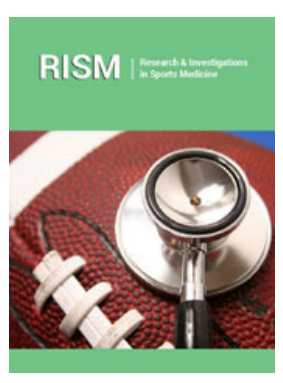

Research \& Investigations in Sports Medicine

Benefits of Publishing with us

- High-level peer review and editorial services

- Freely accessible online immediately upon publication

- Authors retain the copyright to their work

- Licensing it under a Creative Commons license

- Visibility through different online platforms 